Original Article

\title{
Upper gastro intestinal foreign bodies in pediatrics patients
}

\author{
Venkatesh M. Annigeri', Bahubali D Gadgade ${ }^{2}$, Rashmi V. Annigeri ${ }^{3} \&$ Anil B. Halgeri ${ }^{4}$ \\ ${ }^{1,4}$ Professors, ${ }^{2,3}$ Assistant Professors, Department of Pediatrics, ${ }^{3}$ Department of Anaesthesiology, \\ SDM College of M edical Sciences \& Hospital, Sattur, Dharwad, Karnataka, India. \\ Correspondence \\ Venkatesh M. Annigeri \\ Professor \& Head , Department of Paediatric Surgery, SDM College of Medical Sciences \& Hospital, \\ Sattur, Dharwad 580009, Karnataka, India. \\ Mobile : +91 9379907621 E-mail : drvenkateshpgi@rediff.com
}

\section{Abstract}

Aim:Analyzeexperience with presentation, diagnosis and management of accidental ingested upper digestive tract foreign bodies in children.

Materials:A prospective study of 60 pediatric patients from July 2009 to July 2014 with history of accidental ingested upper gastro intestinal foreign bodies. All patients were studied for age, gender, complaints, duration, site of impaction, type and complications. Radiological investigations were taken according to the case. Direct laryngoscopy and Magill forceps or flexible esophagoscopy has been used for retrieval of foreign bodies.

Results: Sixty cases were analyzed age between 6 months to 13 years. Male 42 and female 18. Age group 6 months to 6 years constitutes $85 \%$. Thirty six (60\%) patients arrived to hospital within 24 hours. Difficultly in swallowing (70\%) was the most frequent symptom. M ost foreign bodies were coin in the upper esophagus (70\%). Preexisting esophageal disease was present in 20\%. Out of 60 patients twenty four (40\%) FB retrieved using Magill forceps and rest with Flexible esophagoscopy (60\%). Foreign bodies were successfully removed without major complication in all cases. Mucosal erosions were seen in four patients after extraction. All patients except 4 were discharged within 24 hours after the procedure.

Conclusion: Children between 6 month to 6 years is the commonest age group affected. Magill forceps with the aid of a direct laryngoscope is a safe and effective method for proximal esophageal foreign body removal. But flexible esophagoscopy remains the safest method of upper digestive tract foreign body extraction.

Keywords: Foreign body, Coin, Esophagoscopy, Magill forceps

\section{Introduction}

Pediatrics gastrointestinal foreign bodies(FB) is a common pediatric surgical emergency that faces the pediatric surgeons. Gastrointestinal FB is common and potentially serious cause of morbidity and mortality in children. The majority of ingested foreign objects will pass spontaneously. However, $10 \%$ to $20 \%$ may become lodged in the esophagus or other locations in the gastrointestinal tract and may require nonoperative intervention, and $1 \%$ or less will require surgery.

\begin{tabular}{|c|}
\hline Access this article online \\
\hline Quick Response Code \\
\hline \\
\hline
\end{tabular}

\section{$(1,2,3)$ Extrapolation of} the western data may not be relevant to our circumstances. The present study analyses the results our own 5 years' experience with diagnosis, presentation and management of accidental ingested upper digestive tract foreign bodies in children.

\section{Material and methods}

This study consisted of 60 consecutive patients presenting with history of accidental ingested upper gastro intestinal FB and admitted to the Pediatric surgery department of SDM medical college and hospital Sattur, Dharwad, Karnataka between July 2009 and July 2014. Our hospital is the one of the tertiary referral central in north Karnataka.

The detailed history was recorded and a clinical examination performed. All patients were studied for gender, age, complaints, duration, time elapsed before coming to hospital, site of impaction, type and complication encountered are recorded. Radiological investigation was taken according to the case. Direct laryngoscopy and Magill forceps or Flexible 
esophagoscopehas been used for retrieval of foreign bodies. All patients were fasting for not less than 4 hours. All procedures were performed as inpatients procedure under general anesthesia which was delivered via mask for Magill forceps procedure, while those undergoing oesophagoscopy had anaeshesia delivered via endotracheal tube. There were no anaeshesia related complications. After the procedure completion, type and site of the foreign body and state of mucosa at the site of impaction were recorded. All patients except 4 were discharged within 24 hours after the procedure. The study was approved by the institutional review board and had informed consent of all the parents.

\section{Results}

There were a total of sixty children. Out of 60 cases forty two $(70 \%)$ were males and eighteen $(30 \%)$ were females. Fifty one (85\%) patients were aged six months to six years. Nine (15\%) were more than 6 years old. (Table-1)

At presentation, the foreign bodies had been in the upper gastro intestinal fewer than $24 \mathrm{hr}$ in 36 patients (60\%), between 1 day and 1 week in 12 patients (20\%), and from 1 week to 4 months in 6 patients (10\%). In $6(10 \%)$ the duration was unknown. Fifty one (85\%) patients had definitive history of FB ingestion. Predisposing esophageal disease seen in $20 \%$ of patients. Most commonly postoperative esophageal atresia seen in $6(10 \%)$ patients and the history of caustic stricture and postoperative fundoplication present in one patient each

The commonest presenting complaints were difficulty of swallowing occurring in forty two $(70 \%)$ followed by vomiting in $30(50.6 \%)$ patient, drooling of saliva in $12(20 \%)$ and repeated respiratory tract infections in $3(5 \%)$. Whereas twelve (20\%) patients were asymptomatic. The most common FB ingested was coin recorded in $48(80 \%)$ patients, followed by metallic and food materials $12(20 \%)$. Metallic and food materials included seeds in five (8\%) patients, battery in three (5\%). safety pin in three $(5 \%)$ and shaving blade in one patient.

Radiopaque objects were detected in fifty five (92\%) patients, while the radiology investigation was negative in five $(8 \%)$. Depending on the plain $x$ rays majority of the foreign bodies were impacted in the upper $1 / 3$ of the esophagus (just below the cricophyarngeal muscle) 70\% (42 patient), and the second most common site was the lower $1 / 3$ of esophagus $20 \%$. While the least number $5 \%$ ( 5 patients) each FB were recorded in the Middle $1 / 3$ of esophagus and stomach.

Total sixty patient have been subjected to intervention for the removal of their impacted foreign bodies. Twenty four (40\%) F B were removed by direct laryngoscope and M agill forceps and thirty six (60\%) patient were removed by flexible esophagoscopy. All of the cases had smooth uneventful intervention apart from two of the patients. One of them developed bleeding due to mucosal injury during extraction of a razor, in which the patient kept on nothing by mouth, i.v fluid, systemic antibiotic and monitoring clinically and radiologicaly. There was one patient of lower esophageal FB (tamarid seed) which was difficult to grasp, which was removed with multiple attempts. Foreign bodies were successfully removed without major complication in all cases. Significant mucosal erosions were seen in four $(6 \%)$ patients after extraction all were improved with conservative treatment.

Table 1 : Age and Sex distribution of cases

\begin{tabular}{|l|c|c|}
\hline & \multicolumn{2}{|c|}{ Age in months } \\
\hline Sex & Male $(n=42)$ & Female $(n=18)$ \\
\hline$\varangle 6$ month $(n=0)$ & 0 & 0 \\
\hline 6month -6 years $(n=51)$ & 36 & 15 \\
\hline$>$ 6years $(n=9)$ & 6 & 3 \\
\hline
\end{tabular}

\section{Discussion}

The majority of foreign body ingestions occur in the pediatric population, with a peak incidence between the ages of 6 months and 6 years. $(1,2)$ In our study also FB ingestion is common in children between 6 months to 6 years. The presence of symptoms is significantly associated with gastrointestinal FB, but the absence of symptoms does not reliably exclude the possibility of an esophageal foreign body where a patient may have a foreign body lodged in the esophagus and be completely asymptomatic, for these reason radiological studies can be beneficial in 


\section{Figure 1}

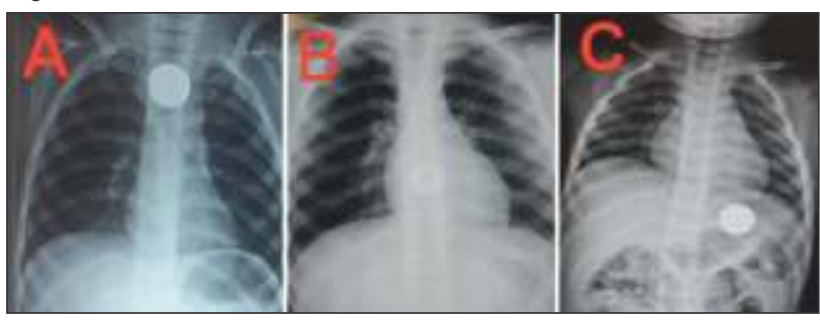

Figure 1A: Xray chest showing coin struck at upper eso phagus. Figure 1B: X ray chest showing coin struck at lower eso phagus. Figure 1C: X ray chest and abdomen showing coin in the stomach

\section{Figure 2}
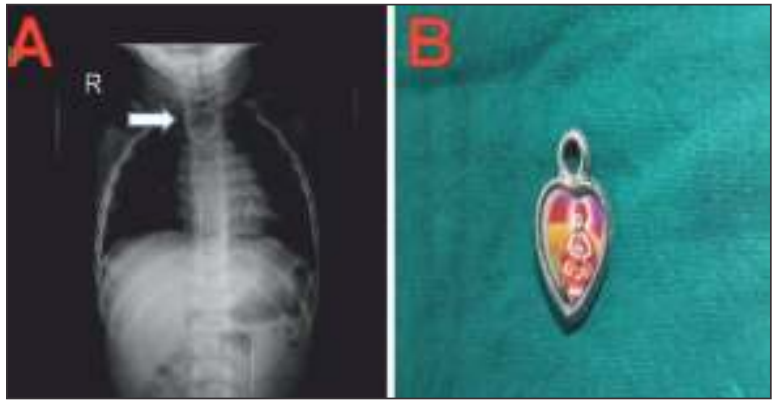

Figure $\mathbf{2 A}$ : $\mathrm{X}$ ray of the neck and chest showing metallic foreign body (pendent) (arrow) in the upper esophagus

Figure 2B : Endoscopically removed metal pendent

Figure 3

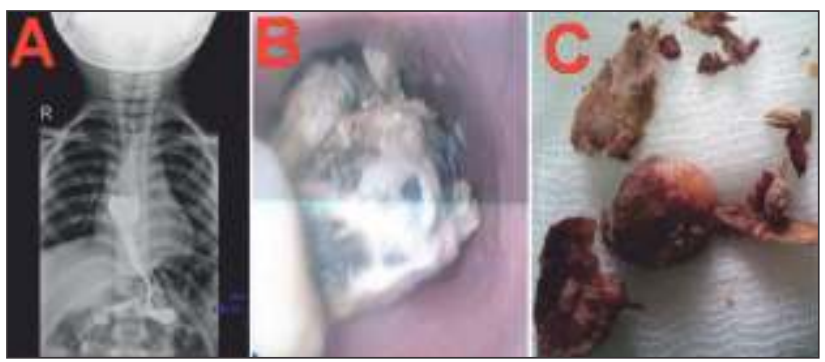

Figure 3A : Barium swallow showing narrowing at junction of upper two-third and lower one-third of esophagus.

Figure 3B: Endoscopic view of impacted tamarind seed

Figure 3C: Endoscopically extracted tamarind seed pieces

\section{Figure 4}
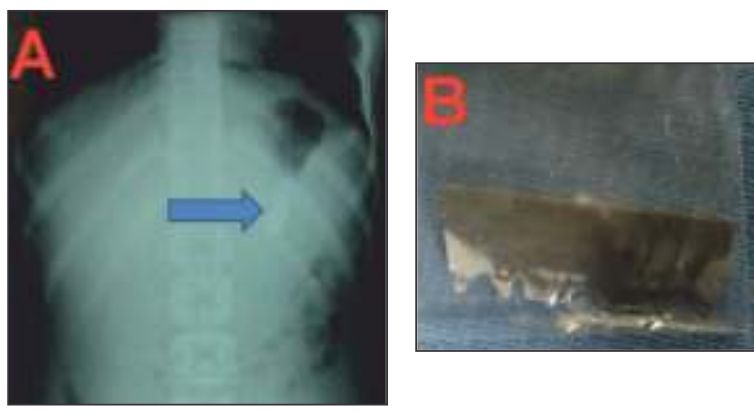

Figure $4 \mathrm{~A}$ : $\mathrm{X}$ ray of the abdomen showing shaving blade (arrow) in the stomach.

Figure 4B: Endoscopically removed shaving blade the management of suspected foreign body ingestions. (1) In our study twelve (20\%) were asymptomatic and fifteen percentage of patients do not have history of $\mathrm{FB}$ ingestion. This result is recorded in other studies and consistent with our present study. $(4,5)$

Common signs and symptom in patients with a foreign body include dysphagia, drooling, vomiting, gagging and anorexia. Significant respiratory symptoms such as coughing, chest pain, stridor, hemoptysis and chronic upper respiratory tract infection are more common weeks or months after ingestion $(6,7)$. In our study most of our patients presented with Dysphagia $(70 \%)$, Vomiting(50\%), Drooling $(20 \%)$. This result is recorded in other studies and consistent with our present study $(7,8)$.

Types of the foreign bodies ingested by the patient were versatile but the most common type was metallic objects $70 \%$ including coins, pins etc. However, all types of foreign bodies could be found in any age group, but the frequency of the type is very much age related. Coins were the most common reported foreign body. $(7,8)$ Our series also confirmed that the most commonly retained esophageal foreign body in these infants and children.

Predisposing esophageal disease like esophageal strictures, particularly those related to esophageal atresia after surgery, were a common predisposing factor to recurrent esophageal foreign body retention in infants and children This result is recorded in other studies and consistent with our present study $(2,3)$. Site of foreign body impaction in the esophagus was consistent with the results of other similar studies $(2,3)$ where the most common site was at the lower border of cricophyarngeal muscle (70\%), and this is expected anatomically because the upper esophageal sphincter is the first narrowing which faces the ingested foreign body $(2,3)$. Next common site is the middle esophagus. The site of impaction also could be influenced by preexisting esophageal pathology.

In symptomatic patients, diagnosis and treatment are usually straightforward. Because foreign bodies impacted in the upper or mid esophagus have little prospect of 
passing spontaneously, instrumentation should be pursued immediately (9). Therefore, all patients with suspected foreign body ingestions should undergo immediate chest radiography or esophagoscopy exclude retention, even if the child is asymptomatic. Biplane radiographs identify most true foreign objects. Radiographs can confirm the location, size, shape, and number of ingested foreign bodies and help exclude aspirated objects. However food particles, wood, plastic, glass, and thin metal objects are not readily seen. The benefits of obtaining $x$-ray on a patient with known or suspected foreign body ingestion are well described. An important role of $\mathrm{x}$-ray especially in radiopaque objects is that it can help to determine if there is more than one foreign body ingested. An important point to remember is that the patient still can have esophageal foreign body despite a normal $x$-ray and asymptomatic patient $(4,5,9)$. In our study $80 \%$ of the patient had the positive $x$-ray findings.

The method of intervention used in our study was either Magill forceps procedure or flexible oesophagoscopy, similar as other studies. $(9,10.11)$ Several different treatment options exist for impacted upper gastrointestinal FBs. These include observation, esophageal bougienage, Foley catheter extraction, and penny pincher technique, flexible and rigid esophagoscopy. $(12,13,14,15)$ But we did not use any of them because with the long accumulating experience in our institute in adults patients with the upper gastrointestinal FBs they found that flexible esophagoscopy safer, more reliable and quick technique for removal of all types of foreign bodies with very high success rate.

Direct laryngoscopy and Magill forceps is an option to remove objects lodged at or above the cricopharyngeus. Otherwise flexible endoscopy may be performed when laryngoscopy is unsuccessful or for treatment of objects

\section{References}

1. Webb WA. Management of foreign bodies of the upper gastrointestinal tract: Update. GastrointestEndosc 1995;41:39-51.

2. Binder $L$, Anderson WA. Pediatric gastrointestinal foreign body ingestions. Ann Emerg Med 1984;13:112-127.

3. Velitchkov NG, Grigorov GI, LosanoffJE. Ingested foreign bodies of the lodged below this area. The current technique is predicated on the fact that coins lodged in the upper esophagus generally are firmly, not rigidly, impacted, and they always are situated in the coronal plane. Only if coin seen clearly. If the coin is not seen, the anesthetic administration is converted from mask to endotracheal, and the coin is extracted using a flexible endoscope. Removal with flexible endoscopes has a high success rate Endoscopic retrieval of sharp objects may be accomplished with retrieval forceps,a retrieval net, or a polypectomy snare. Foreign body forceps, snare, or retrieval net. The risk of mucosal injury during retrieval can be minimized by orienting the object with its point trailing during extraction, by using an overtube, or by fitting the endoscope with a protector hood. We used over tube for sharp blade which preset in stomach. None of our patients required surgery for the extraction of his foreign body compared to other studies where $1.66 \%$ and $2 \%$ required surgery. $(15,16)$ M ay be this is because the more cases are collected the more difficult and rare cases will appear. Only four of our patient developed mucosal injury following extraction of sharp objects, all were improved with conservative treatment

\section{Acknowledgement}

We are grateful to the Medical Director, SDM hospital Dharwad for permission to use the hospital data and records

\section{Conclusion}

Children between 6 month to 6 years were the commonest age group affected by gastrointestinal FB impaction. Upper third of eso phagus was the commonest site of foreign body impaction. Direct laryngoscopy using Magill forceps is a safe and effective method in removing upper esophageal foreign bodies minimizing the need for muscle relaxant and endotracheal intubation in selected cases Flexible esophagoscopy remains the safest method of esophageal foreign body removal in infants and children.

gastrointestinal tract: retrospective analysis of 542 cases. World J Surg 1996; 20:1001-5.

4. Chen MK, Beierle EA. Gastrointestinal foreign bodies. Pediatr Ann 2001;30(12): 736-742.

5. Eisen GM, Baron TH, Dominitz JA. Guideline for the management of 
ingested foreign bodies. GastrointestEndosc 2002;55(7):802-6.

6. Kay, M. Wyllie, R. Pediatric foreign bodies and their management. CurrGastroenterol Rep 2005; 7:212.

7. Athanassiadi K, Gerazounis M, M etaxas E, Kalantzi N. M anagement of esophageal foreign bodies: a retrospective review of 400 cases. Eur J Cardio-ThoracSurg 2002; 21:653-6.

8. Arana A, Hauser B, Hachimi-Idrissi S, Vandenplas Y. Management of ingested foreign bodies in childhood and review of the literature. Eur J Pediatr 2001; 160:468.

9. Ginsberg, GG. M anagement of ingested foreign objects and food bolus impactions. GastrointestEndosc 1995; 41:33.

10. Cheng, W, Tam, PK. Foreign-body ingestion in children:experience with 1,265 cases. J PediatrSurg 1999; 34:1472

11. Janik, JE, Janik, JS. M agill forceps extraction of upper esophageal coins.
J PediatrSurg 2003; 38:227.

12. Dahshan, AH, Kevin Donovan, G. Bougienage versus endoscopy for esophageal coin removal in children.J ClinGastroenterol 2007; 41:454.

13. Waltzman, ML. Management of esophageal coins. CurrOpinPediatr 2006; 18:571.

14. Velitchkov, NG, Grigorov, GI, Losanoff, JE, Kjossev, KT. Ingested foreign bodies of the gastrointestinal tract: retrospective analysis of 542 cases. World J Surg 1996; 20:1001.

15. Pellerin, D, Fortier-Beaulieu, M, Guegen, J. The fate of swallowed foreign bodies: experience of 1250 instances of subdiaphragmatic foreign bodies in children. ProgPediatrRadiol 1969; 2:302

16. Hachimi-Idrissi, S, Corne, L, Vandenplas, Y. Management of ingested foreign bodies in childhood: our experience and review of the literature. Eur J Emerg M ed 1998; 5:319. 